\title{
Textos de Avaliação na WEB: PARA UMA POLÍTICA DE INCENTIVO ÀS PUBLICAÇÕES VIRTUAIS
}

\section{Zacarias Jaegger Gama}

\begin{abstract}
Resumo
0 presente artigo focaliza os textos acadêmicos de avaliação veiculados na WEB. Ele objetiva levantar alguma hipótese que verdadeiramente possa explicar porque os Programas de Pós-graduação situados nas regiões Norte, Nordeste e Centro têm pequena visibilidade de produção de tais textos fora dos meios físicos tradicionais, com desprezo pelas possibilidades oferecidas pelo ambiente virtual, mais rápido e econômico. Em seu desenvolvimento, este artigo busca superar as hipóteses de senso comum e se propõe um détour considerando o fenômeno em sua essência para ultrapassar a sua pseudoconcreticidade. Seu pressuposto central é que 0 Qualis, implementado pela CAPES para avaliar as publicações acadêmicas é um fator de inibição e de impedimento de visibilidade de tal produção, que também contribui para reproduzir determinações e modos de agir ideológicos característicos dos centros editoriais e de acumulação do capital no país.
\end{abstract}

Palavras-chave: Avaliação. Textos acadêmicos de avaliação. Programas de Pósgraduação.

\footnotetext{
${ }^{1}$ Doutor em Educação pela Universidade Federal do Rio de Janeiro, Docente do Programa de Pós-Graduação em Políticas Públicas e Formação Humana da Faculdade de Educação da Universidade Estadual do Rio de Janeiro. Membro do Grupo Projeto Integrado UFF-FIOCRUZUERJ, do Grupo de Pesquisa Trabalho, Educação e Políticas Públicas e do Grupo de Pesquisa Políticas Públicas, Gestão e Avaliação.
} 


\section{EVALUATION TEXTS IN WEB: FOR A POLICY TO PROMOTE VIRTUAL PUBLICATIONS ABSTRACT}

This article examines the academic evaluation texts made available through the WEB. Its objective is to propose a hypothesis that can truly explain why the graduate programs situated in the North, Northeast and Center regions have little visibility in terms of their production of such texts outside of the traditional physical media, reflecting a disdain for the possibilities offered by the virtual environment, which is faster and more economical. This article tries to overcome the common sense hypotheses and proposes a detour that considers the phenomenon in its essence in order to get beyond its pseudo-concreteness. Its central argument is that the Qualis, implemented by CAPES to evaluate academic publications is a factor that inhibits and impedes that type of production, which in turn contributes to reproducing decisions and ideological modes of action that are characteristic of the centers of publication and capital accumulation in this country.

Keywords: Evaluation. Academic evaluation texts. Graduate programs

\section{INTRODUÇÃO}

0 texto Avaliação Educacional: Geografia de textos na Internet explorações iniciais (GAMA; COELHO; CAMELO, 2007) é o ponto de partida da presente elaboração. Seu objeto de análise circunscreveu-se às produções acadêmicas de avaliação educacional em circulação na WEB e, nos seus limites, ensaiou uma geografia deles propondo-se a investigar em que lugares ocorrem tais produções ${ }^{2}$.

Nestas explorações iniciais tais lugares puderam ser determinados com alguma imediatidade e sem muitas surpresas, como se pode ver no gráfico a seguir:

${ }^{2} 0$ artigo que apresenta os lugares desta produção está publicado com o título "Avaliação Educacional: Geografia de textos na Internet - explorações iniciais" na Revista Iberoamericana de Educación, n 45/1, janeiro de 2007 e encontra-se completo em: www. rieoei.org/deloslectores/1485Gama.pdf 


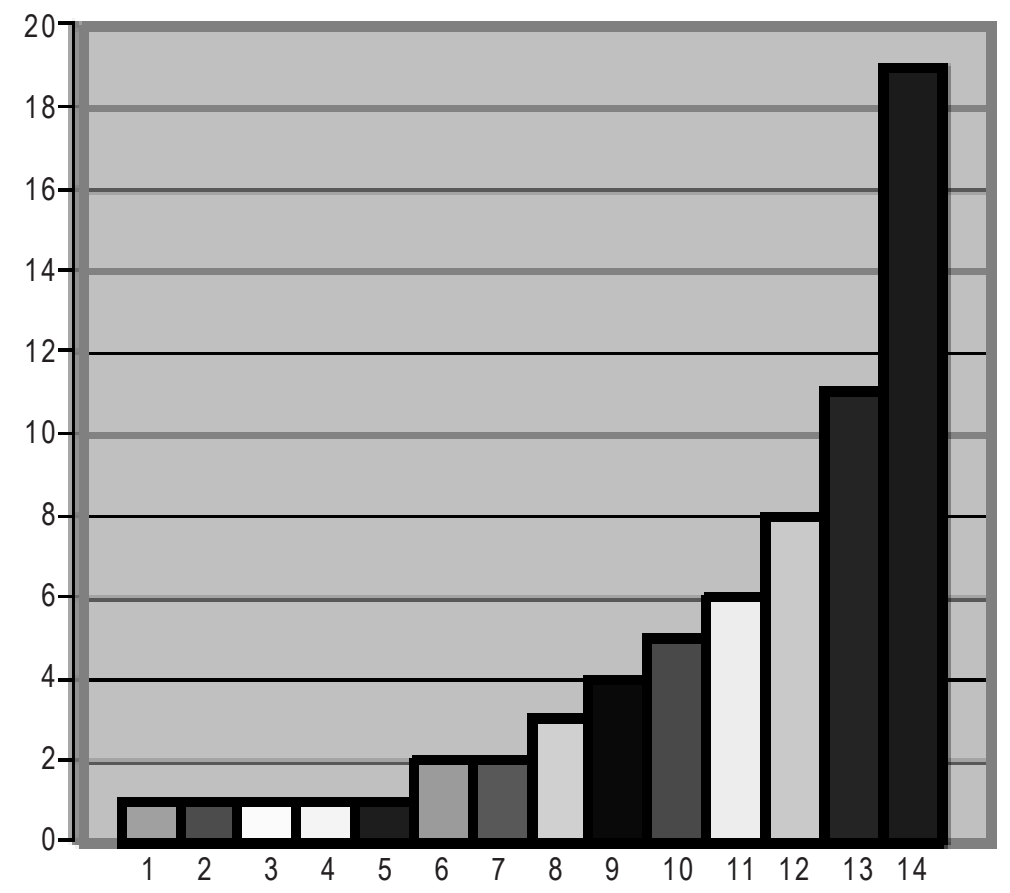
1. Espírito Santo
2. Mato Grosso
[3. Rio Grande do Norte
4. Rio Grande do Sul
5. Pará
․ Ceará
7. Goiás
[8. Minas Gerais
9. Santa Catarina
10. Bahia
口11. Paraná
[12. Distrito Federal
13. Rio de Janeiro
14. São Paulo

Fonte: Pesquisa Arqueologia de Textos de Avaliação na WEB. Texto Avaliação Educacional: Geografia de textos na Internet.Explorações iniciais (GAMA; COELHO; CAMELO,2007).

São coincidentes os lugares de maior produção de textos acadêmicos de avaliação com os centros de concentração do capital e, por conseguinte, de mais desenvolvimento tecnológico e científico. São Paulo, Rio de Janeiro e Brasília destacam-se ainda pela proporção de moradores com acessos a computadores. Segundo dados do IBGE há somente em São Paulo aproximadamente 2,17 milhões de domicílios particulares com acesso à Internet, o que corresponde ao percentual de $2,47 \%$ do total de sua população. No Rio de Janeiro, para o conjunto de 0,77 milhões de habitantes, a proporção é igual a 2,13\%, e em Brasília/Distrito Federal, para o conjunto de 0,16 milhões, a proporção é de 3,12\% (IBGE, 2005). 
Além destes principais locais, destacaram-se ainda as produções acadêmicas realizadas em outros estados: Paraná, Bahia, Santa Catarina e Minas Gerais formam outro grupo importante nesta produção de textos acadêmicos de avaliação, mas em menor escala.

Segundo a mesma fonte (IBGE, 2005), os estados das regiões Norte, CentroOeste e Nordeste são os que têm o menor acesso à Internet e à rede de telefonia. Eles seriam então os que apresentam a menor produção de textos de avaliação na WEB e teríamos ai uma constatação por demais óbvia apenas considerando o quantitativo de acessos. Mas, se queremos ir além da obviedade do mundo fenomênico é indispensável que façamos um détour mais determinado para chegarmos à essência do fenômeno. Aguça nossa curiosidade a irrisória produção acadêmica de textos de avaliação em toda esta área geográfica quando sabemos haver aumentado significativamente o número de programas de pós-graduação (PPGs) em Educação com cursos de Mestrado e Doutorado e que a maioria deles têm conceito 4 (quatro) e boa produção intelectual segundo a CAPES.

No quadro a seguir mostramos a distribuição deles, bem como os conceitos obtidos em 2004, indicados nos parênteses.

\section{Geografia dos cursos de Mestrado e Doutorado EM EDUCAÇÃO}

\begin{tabular}{|l|l|l|l|l|l|l|l|l|ll|l|l|l|}
\hline \multicolumn{1}{|l|}{ Região Norte } & \multicolumn{4}{l|}{ Região Nordeste } & \multicolumn{4}{|l|}{ Região Centro-Oeste } \\
\hline IES & UF & M & D & IES & UF & M & D & IES & UF & M & D \\
\hline UFAM (4) & AM & X & - & UFBA (4) & BA & X & X & UNB (4) & DF & X & X \\
\hline UFPA (4) & PA & X & - & UFC (4) & CE & X & X & UFG (4) & GO & X & X \\
\hline UEPa (NA) & PA & X & - & UFAL (3) & AL & X & - & UFMT (4) & MT & X & - \\
\hline & & & & UFMA (3) & MA & X & - & FUFMS (4) & MS & X & X \\
\hline & & & & UFPB/J.P. (4) & PB & X & X & & & & & \\
\hline & & & & UFPE (5) & PE & X & X & & & & & \\
\hline & & & & FUFPI (4) & PI & X & - & & & & & \\
\hline & & & & UFRN (5) & RN & X & X & & & & & \\
\hline & & & & FUFSE (4) & SE & X & - & & & & & \\
\hline & & & & UNEB (4) & BA & X & - & & & & & \\
\hline
\end{tabular}

Fonte: CAPES (2004). Disponível em: http://servicos.capes.gov.br-2003_038_Sintese.pdf. 
Mais ainda nos instiga o fato dos PPGs das universidades federais da Bahia, do Ceará, Piauí, Pernambuco e Sergipe terem cursos bem conceituados de Mestrado e Doutorado em Educação; disciplinas curriculares diretamente voltadas para a avaliação em educação, assim como para a avaliação de sistemas, de políticas e da aprendizagem e serem, em princípio, capazes de desenvolver uma produção acadêmica proporcional aos conceitos obtidos (Capes, 2004). Ficamos mais incitados quando sabemos estarem todas estas universidades conectadas à Internet com acessos de alta velocidade (banda larga) e ser possível a qualquer pesquisador, mestrando e doutorando veicular um texto acadêmico no ciberespaço, com rapidez e baixo custo.

Ora, assim sendo, tem sentido indagar: por que a produção acadêmica voltada para os estudos avaliacionais nestes PPGs é ainda insignificante em ambiente virtual? Nós estamos apostando na positividade de tal ambiente na medida em que os saberes ai veiculados podem fecundar-se dialeticamente, engendrar novos conhecimentos, conceitos e experiências, e permitir que tais conhecimentos saberes sejam mais eficientemente socializados entre indivíduos e grupos sociais, mesmo que habitem distantes e remotas localidades.

Com bastante imediatidade, talvez pudéssemos trabalhar com a hipótese muito simples de constituição de uma nova geopolítica nacional que, dialeticamente, vem sendo construída com o desenvolvimento do ciberespaço, contando com novos padrões de mobilidade que se impõem a partir da concentração de serviços tecnológicos e telemáticos de qualidade em determinadas áreas. Contudo, a acelerada informatização das universidades federais Brasil afora, por si só seria suficiente para negá-la. Uma rápida navegação pelos seus portais WEB nos dá uma dimensão bem nítida dos seus níveis de desenvolvimento informático. Talvez também fosse possível pensar nos deslocamentos de capitais intelectuais e sociais e na convergência deles para áreas mais ricas com promessas de novos e privilegiados ambientes de infoinclusão, com vistas de acesso ao que há de melhor. Mas, o simples incluir-se em determinadas "ilhas" tecnológicas e telemáticas situadas ao Sul do país, independentemente do que isto pode significar individualmente, implica hoje em negar a possibilidade de existência de bolsões tecnológicos, concentração de serviços e, também, de capital intelectual ao menos nas universidades destas regiões. Talvez ainda pudéssemos, com boa dose de preconceito, não admitir que nestas regiões, de 2004 para cá, tem havido um crescimento vertiginoso de acesso à Internet, inclusive pelas classes mais baixas da população. Em pesquisa realizada pelo Instituto Brasileiro de Opinião Pública e 
Estatística (IBOPE) verificou-se que esse acesso no Brasil saltou de 4\% para 11\% em 2005. A maioria o faz a partir de computadores em seus locais de trabalho e estudo e em casa de amigos e parentes (IBOPE, 2005).

A aceitação de qualquer das possibilidades acima sugere, então, forte desprezo pelo curso construtivo de um novo estilo cultural, produzido por uma combinação de fatores tecnológicos e sociais, característico de um novo modo de desenvolvimento que Castells (2000) denomina de informacionalista, ou seja de expansão e atualização do modo de produção capitalista. No entanto, por mais que possamos discordar deste autor, devemos ainda assim concordar com ele ao afirmar que os processos de geração de conhecimento e de comunicação já estão profundamente transformados pelo paradigma informacional e conectados ao ciberespaço.

A ausência de textos acadêmicos de avaliação produzidos por estudiosos das regiões Norte, Nordeste e Centro-Oeste, portanto é lastimável, em particular frente à possibilidade de socialização deles e de nos encaminharmos para o que Chartier (1999, p. 117) julga ser plausível:

com o texto eletrônico, a biblioteca universal torna-se imaginável, porque pela primeira vez, na história da humanidade, a contradição entre o mundo fechado das coleções e o universo infinito do escrito perde seu caráter inelutável.

0 fato de estarmos encampando esta idéia de biblioteca universal vai além de qualquer modismo ou de alguma atitude colonizada. Nós acreditamos que sua constituição é deveras importante para democratizar acessos a saberes, conceitos e experiências em especial para aqueles que se situam geograficamente em lugares remotos, distantes dos centros culturais mais dinâmicos do país. Além disso, tal biblioteca pode ser importante mediação a serviço da emancipação no âmbito das relações sociais determinadas historicamente.

A razão desta produção quantitativamente quase imperceptível apresentada pelos cursos de pós-graduação das regiões Norte, Nordeste e Centro-Oeste é, a partir desse enfoque, a questão central que nos preocupa e que nos leva à sua investigação em bases empíricas e teóricas.

Para abordá-la inicialmente fizemos investigações empíricas e em seguida consideramos algumas hipóteses recorrentes na literatura acadêmica sem, entretanto, nos restringimos a elas; tivemos necessidade de avançar para além das mesmas, superando-as. A circunstância nos encaminhou ao exame dos planos 
nacionais de desenvolvimento da pós-graduação brasileira e também ao Qualis, isto é, ao instrumento de classificação de periódicos desenvolvido e aplicado pela Coordenação de Aperfeiçoamento de Pessoal de Nível Superior (CAPES). Nossa pressuposição construída paulatinamente, é que o Qualis tem enorme responsabilidade na obliteração da produção de textos acadêmicos de avaliação nas regiões Norte, Nordeste e Centro-Oeste. Ao defendermos a incorporação pelo Qualis dos textos acadêmicos veiculados pela WEB estamos nos insurgindo contra quaisquer formas de produção e reprodução da alienação e atribuindo às novas tecnologias da informação e da comunicação a possibilidade de dilatação das nossas aprendizagens, sentidos, observações, experiências e trocas.

\section{Hipóteses}

A investigação da produção de textos acadêmicos de avaliação veiculados na WEB conduziu-nos, naturalmente, a focalizar com exclusividade a produção virtual-acadêmica de Instituições Públicas de Ensino Superior (IPES) com cursos de Mestrado e Doutorado, considerando-as como lócus próprio de produção de tais textos e com sujeitos-pesquisadores oriundos de diversas origens sociais. Nossa investigação foi abrangente, apesar de estarmos com maior focalização nas IPES situadas nas regiões Norte, Nordeste e Centro-Oeste, pelo fato destas regiões terem pequena visibilidade na produção de textos de avaliação em circulação na WEB e estar havendo nelas a expansão da pós-graduação com cursos de Mestrado e Doutorado.

Seguindo o ponto de vista de Chartier (1999, p.12), poderíamos considerar como verdadeira a hipóteses que dificulta a produção eletrônica de textos acadêmicos de avaliação e, por conseguinte a concentração e centralização deles em uma biblioteca universal. 0 cerne desta hipótese é a relutância dos sujeitospesquisadores no que diz respeito à produção de textos eletrônicos, na medida em que escrevê-los na tela do computador "cria uma distribuição, uma organização, uma estruturação do texto que não é de modo algum a mesma com a qual se defronta o leitor" habituado historicamente aos textos tipografados. Esta hipótese pode ainda ser incrementada se levamos em conta o estabelecimento de um acentuado distanciamento entre aquele que pensa e produz e o que lê o texto eletrônico. Para Chartier (1999, p. 16), a mediação do teclado se amplia em relação à maquina de escrever e "instaura um afastamento entre 0 autor e seu texto". 
Outra hipótese sugerida pelo mesmo autor, igualmente bastante plausível, aborda a imaterialidade do texto eletrônico. Neste caso os autores mais presos à "consciência tipográfica" talvez possam se sentir com desconfortos diante "de uma entidade, de uma obra com traços específicos que não são aqueles das formas materiais em que ela se encarna" (CHARTIER, 1999, p. 91). Muitos, por natureza, quiçá se sintam sem condições de sentir a materialidade de sua obra e incapazes de ostentá-la fisicamente.

Outras hipóteses de ordem mais operacional, agora não mais de Chartier, podem nos levar a considerar a infoexclusão de muitos cientistas como resultante dos seus pequenos engajamentos no ciberespaço, da não apropriação da cibercultura, da incapacidade de compartilhar suas produções em meio digital e do sentimento de perplexidade diante das diversas formas de expressão virtual na rede mundial de computadores, ainda não-dominadas por eles. É possível que estes estejam apreciando o computador apenas como uma máquina de escrever sofisticada, com recursos de busca, sem atinar, contudo, para os avanços digitais e as potencialidades favoráveis que a rede mundial de computadores pode oferecer. Mas, apesar do pequeno engajamento e das dificuldades expressas, vale ressaltar o uso crescente das novas Tecnologias de Informação e Comunicação (TICs) mediadas pelo computador e pela comunidade científica. Mesmo que tais dificuldades sejam reais, sempre será possível contar, por exemplo, com fantásticos expertises, isto é, estudantes bolsistas de Iniciação Científica ou outros, conforme nos informa o trabalho conjunto de Costa, Silva e Costa (2006) baseado em autores da temática3.

Todas as hipóteses apontadas acima, em nossa opinião, são apenas plausíveis. A abstração que contêm e os seus níveis de generalização tornam-nas incapazes de explicar o grande volume de produção virtual realizado na Região Sudeste, por exemplo. Ora, ai também há relutâncias, a imaterialidade do texto e a mesma perplexidade de muitos em seus contatos com o mundo digital. Porém, tais hipóteses não são desprezíveis ou simplesmente desprovidas de autoridade; em nossa opinião o caráter delas é o que inviabiliza explicar a regionalização do fenômeno que estamos investigando.

Tal constatação impõe-nos então o exercício de buscar outras pistas, agora nos próprios domínios da pós-graduação no Brasil, aceitando-se o princípio de ser no âmbito do Sistema Nacional de Pós-graduação que ocorrem as mais

${ }^{3}$ Costa e Meadows (2000); Voorbji (1999); Kaminer e Braustein (1998); Cohen (1996). 
importantes atividades de pesquisa científica e tecnológica do país, bem como a produção acadêmica textual, física e virtual, que constitui nosso objeto de investigação. Afinal, interessa-nos questionar por que a homogeneização dos processos de que nos fala Castells (2000, p. 468), na fase informacionalista do desenvolvimento capitalista atual, não contribui para infoincluir a produção de textos acadêmicos de avaliação realizada na rede de programas de pós-graduação das regiões Norte, Nordeste e Centro-Oeste.

\section{Os Planos Nacionais de Desenvolvimento da Pós-graduação}

0 desenvolvimento da Pós-graduação no Brasil tem sido motivo de orgulho para a Coordenação de Aperfeiçoamento de Pessoal de Nível Superior - CAPES, e para a própria Academia. Hoje, pode-se afirmar que se constitui em uma das realizações mais bem sucedidas no conjunto do sistema de ensino brasileiro, conforme o que se lê no Plano Nacional de Pós-graduação - PNPG, para 0 qüinqüênio 2005 - 2010 (CAPES, 2004).

Os PNPGs anteriores (I PNPG, 1975-1979; II PNPG, 1982-1985; III PNPG, 1986-1989) assim como o atual PNPG 2005-2010, sempre entendidos como políticas públicas são responsáveis diretos pelo sucesso da pós-graduação. Foram eles que lhe imprimiram uma direção macro-política, realizaram diagnósticos e estabeleceram metas e ações concretas articuladas a um sistema de financiamento governamental de ciência e tecnologia. Ao mesmo tempo eles institucionalizaram a pesquisa, intensificaram a capacitação do corpo docente, fortaleceram a iniciação científica, enfim, ampliaram a comunidade científica nacional e sua produção intelectual articulada a importantes centros internacionais de pesquisa. Todavia, apesar dessa expansão, continua a persistir hoje uma "distribuição desigual entre as regiões do Brasil, uma vez que o Sudeste concentra 54,9\% dos cursos de mestrado e 66\% dos de doutorado" (CAPES, 2004). As demais regiões ficam bem abaixo destes percentuais, sobretudo quando somente evidenciamos os cursos de doutorado, aqui entendidos como sendo aqueles que se voltam prioritariamente para a formação de pesquisadores e articulam as atividades de ensino e de pesquisa. Assim, a Região Sul apresenta-se com 17,1\% de cursos de doutorado, a Região Nordeste com 10,3\%, a Região Centro-Oeste com 4,1\% e a Região Norte com apenas 1,8\%. Mas, segundo se relata no PNPG 2005-2010: 
Independentemente de políticas direcionadas, nos últimos anos a Região Nordeste alcançou algum destaque, porém, ainda apresenta assimetrias entre os seus estados. No Centro-Oeste o quadro de assimetrias é ainda mais acentuado, uma vez que a pós-graduação concentra-se em Brasília. E no Norte, região de extrema importância nacional pela sua dimensão e diversidade, encontra-se uma pós-graduação incipiente, com concentração em dois estados de uma região de dimensão continental (CAPES, 2004).

As razões para a existência desta assimetria, conforme explicita o próprio PNPG 2005-2010, podem ser atribuídas às tendências das políticas de financiamento de concentrar investimentos públicos nos programas com maior capacidade instalada em termos de recursos humanos qualificados e infra-estrutura. Os programas mais incipientes, neste caso, ficam prejudicados em situação de orçamentos decrescentes e da tendência concentradora de financiamentos na Região Sudeste. Tais razões, ao mesmo tempo em que desvelam o esgotamento da capacidade civilizatória dos PNPGs anteriores, não desconsideram, porém, o destaque que a Região Nordeste alcançou independentemente das políticas direcionadas. Daí tornar-se socialmente relevante investigar porque os PPGs existentes fora do eixo Sudeste-Sul deixam de evoluir em direção a patamares de infoinclusão da produção intelectual que realizam; e quando é plausível a organização de uma biblioteca universal como local virtual de exposição, de alavancagem de novas produções acadêmicas e disponibilização de saberes via WEB, possíveis de serem acessados mesmo dos pontos mais remotos do país.

\section{Mapa da Pós-Graduação em Educação}

Dados colhidos da fonte "CAPES - Relação de Cursos Recomendados e Reconhecidos", nos dão a distribuição dos Programas de Pós-graduação em Educação das Instituições de Educação Superior estaduais e federais. Eles nos mostram a existência consolidada de três Programas de Mestrado na Região Norte, dez Programas de Mestrado e cinco de Doutorado na Região Nordeste e quatro Programas de Mestrado e três de Doutorado na Região Centro-Oeste, evidenciando a assimetria regional e a prevalência das regiões Sudeste e Sul em quantidade de Programas de Pós-graduação em Educação concentrando mais de 60\% deles; nestas duas regiões os mestrados acadêmicos e profissionais e os doutorados somam 1919 cursos. Mas, mais apuradamente, se colocamos o foco de nosso olhar somente nos programas que, independentemente, das suas áreas 
de concentração e linhas de pesquisa em educação têm alguma oferta disciplinar relativa à avaliação, os dados mudam drasticamente. Diversos programas das Regiões Norte, Nordeste e Centro-Oeste, ao contrário dos programas situados na Região Sudeste, demonstram clara preocupação com os estudos avaliacionais, talvez por entenderem a avaliação da mesma forma que Dias Sobrinho e Ristoff (2002, p.8), isto é, "como um fenômeno de grande centralidade" no cotidiano das nossas instituições escolares”. Somente na Região Nordeste cinco programas têm em seus planos curriculares a disciplina avaliação, praticamente igualandose à quantidade de programas da Região Sudeste que a oferecem, oito no total, e superando a Região Sul. Nesta, apenas dois programas oferecem-na.

Por que a produção acadêmica de textos virtuais de avaliação realizada nas regiões Norte, Nordeste e Centro-Oeste têm então tão pouca presença na WEB? 0 que explica tal fato?

Talvez seja mesmo o caso de dar razão a Chartier (1999) ao considerar o desconforto dos autores diante da imaterialidade do texto eletrônico, do aprisionamento à consciência tipográfica e do embaraço no trato com uma obra de traços específicos? Acreditamos, com já foi dito, ser impossível tal possibilidade. Assim, antes de qualquer movimento conclusivo e apressado preferimos ainda examinar outro instrumento das políticas públicas de desenvolvimento da pósgraduação no Brasil concebido pela Coordenação de Aperfeiçoamento de Pessoal de Nível Superior. Este instrumento é denominado de Qualis. 0 que nos move nesse sentido é a idéia de superar preconceitos e questionar certas formas de produção e reprodução na qual se inserem. Aliás, como diz Fontes (2001, p. 126) com base em Marx: "é a vida social o que permite explicar a emergência e a generalização de determinados valores, e não o contrário".

\section{O Qualis}

A CAPES reconhece ser significativa a expansão da produção intelectual dos pesquisadores brasileiros em periódicos tipografados de circulação internacional em comparação com a evolução ocorrida na América Latina e no mundo: entre 2001 e 2003, esta produção "quintuplicou e sua participação em relação ao resto do mundo triplicou" (CAPES, 2004). A partir de 1998, tal produção é medida e classificada pelo Qualis desde que veiculada em revistas e outros periódicos físicos com nítidos indicadores de qualidade e com relevância para a área de conhecimento. 
0 Qualis tem o objetivo de atender às necessidades do sistema de avaliação da CAPES e se baseia em informações fornecidas pelos programas em instrumentos específicos de coleta de dados. Suas finalidades iniciais visavam tão somente à classificação dos veículos de publicação impressa, mas com o passar do tempo tornou-se estimulador de publicações em outros veículos enquadrados nas categorias mais valorizadas das áreas de conhecimento e a indicar aqueles de maior relevância (CAPES/DAV, 2006). De certa forma direciona e monitora a divulgação da produção acadêmica impressa, inclusive para outros veículos considerados como opções importantes para divulgações. Cada área, então, atribui graus de relevância às publicações dos seus pesquisadores, tendo como critério a qualidade e o âmbito de divulgação: internacional, nacional e local. A CAPES, conforme seus objetivos de aperfeiçoamento de pessoal de nível superior, disponibiliza na WEB os periódicos qualificados e impressos. Seu portal de livre acesso socializaos virtualmente depois de impressos, reproduzindo textos completos, bases de dados referenciais com resumos, patentes, teses, dissertações, estatísticas; assim como outras publicações de acesso gratuito na Internet, selecionadas pelo nível acadêmico e mantidas por importantes instituições científicas, profissionais e por organismos governamentais e internacionais.

0 impacto do Qualis sobre a produção acadêmica impressa é grande e leva pesquisadores de outras regiões à disputa de espaços nestes periódicos impressos de qualidade apurada, às vezes esperando meses para publicarem os seus textos, tão grandes as filas. A valorização dos currículos construídos nesta mesma região, por sua vez, obedece a este ritual e ao natural desprezo dos veículos de natureza virtual. As publicações eletrônicas, com efeito, somente passam a ter valor depois de veiculadas fisicamente; não por acaso são poucos os textos publicados direta e exclusivamente em ambiente digital, principalmente nas regiões Norte e Nordeste.

Como se deduz, o incremento de publicações na WEB com exclusividade, mesmo implicando em barateamento dos custos de publicação, agilidade e flexibilidade, além de universalidade e interatividade, precisa ainda vencer 0 reprodutivismo da consciência tipográfica subjacente no Qualis, da qual nos fala Chartier (1999). Vencendo-o seria mais fácil e rápido aproximarmonos do sonho da biblioteca universal perseguido desde a antiga Alexandria e, atualmente, tornado bastante viável pela "comunicação à distância, propiciada pelas redes eletrônicas, que dá novo alento a este sonho, em que toda a 
humanidade participaria do intercambio, inclusive de julgamentos" (Chartier, 1999). Estaríamos, também, mais próximos da possibilidade de cada um ser leitor e autor ao mesmo tempo podendo emitir juízos sobre as instituições e as publicações e, de igual modo, refletir sobre o juízo emitido pelos outros. Mais explicitamente a existência de um Qualis eletrônico poderia democratizar e dar visibilidade com maior rapidez aos textos acadêmicos de relevância, produzidos em áreas distantes dos tradicionais centros de produção acadêmica situados ao Sul.

\section{CONSIDERAÇÕES FINAIS}

A questão que nos moveu no presente texto - por que a Internet, esta "biblioteca universal imaginável", auto-organizável e em permanente mutação, apresenta-se subutilizada por acadêmicos brasileiros das regiões Norte, CentroOeste e Nordeste das Instituições de Ensino Superior, federais e estaduais, como lugar de exposição/publicação dos seus mais recentes estudos de avaliação educacional? - como pudemos analisar, não admite respostas imediatas, hipóteses generalistas e abstrações teóricas. Aliás, como Kosik (1976) já nos indicou, pode o mundo das aparências nos levar a formas ideológicas condicionantes de nosso agir.

0 détour que nos impomos, forçando-nos a abandonar as formas fenomênicas das coisas e a cindir o único, permitiu-nos trazer à luz a opressão imposta pelos meios tipográficos concentrados ao Sul do país e pelo Qualis, obliterando a produção virtual de textos acadêmicos de avaliação produzidos nas regiões Norte, Nordeste e Centro-Oeste.

Bastou o desprezo às representações e ao pensamento comum, bem como à focalização dos Programas de Pós-graduação nestas Regiões, o oferecimento de disciplinas curriculares ligadas à avaliação, assim como o potencial de produção intelectual dos seus docentes e discentes para que se colocasse luz sobre uma produção virtual de textos acadêmicos de avaliação ainda reprimida. Fora do mundo fetichizado da concentração do capital e das velhas práticas de informação e comunicação, há decerto uma produção acadêmica virtual em que há ainda um devem, bastando-lhe tão somente a existência de condições objetivas para se realizar.

A CAPES e o seu Qualis podem criá-las e incentivá-las. Não é difícil que 
o Qualis deixe de se apresentar contraditoriamente como incentivador de novas publicações físicas e instrumento de restrição às publicações acadêmicas virtuais que ainda não são objetos de preferência dos programas. Como fator de inibição e de não democratização das publicações ele tem impacto sobre a disponibilidade das palavras enunciadas e das coisas representadas. Sua força de monitoramento e avaliação da produção, veiculada em periódicos tipografados e qualificados, pressiona a todos no sentido de somente publicar em meio físico, desprezando-se as possibilidades oferecidas pelo ambiente digital, no qual a publicação de revistas igualmente possíveis de serem qualificáveis é pouco onerosa e rápida. Esta mesma força pode libertar os pesquisadores de preferências e caprichos editorialistas do Sudeste porventura existentes, região, aliás, onde se concentram os veículos editoriais mais requisitados.

É, portanto, recomendável que o Qualis passe a incorporar os textos eletrônicos, bem como as revistas. Há na WEB apenas três revistas de estudos avaliacionais. Incrementar uns e outros não constitui nenhuma tarefa hercúlea, basta tão somente que a CAPES oriente novas publicações para 0 ambiente digital. Tampouco haveria dificuldades relativas à indexação das mesmas. As publicações portadoras de tal identificador então poderiam, com facilidade, como nos aconselha Chartier (1999, p. 119), permitir o compartilhamento virtual daquilo que até agora é oferecido apenas em espaços físicos onde o leitor e o livro deveriam estar juntos, mesmo que tais espaços ainda não estejam democratizados pelo país afora. Apesar das mais de 14 mil bibliotecas públicas e comunitárias catalogadas, poucas são acadêmicas e atualizadas. A maioria é simples e de pouca qualidade, com funcionamento precário e visando atender às demandas imediatas de determinadas comunidades de baixa renda (ECOFUTUR0, 2006).

Para encerrar, vale dizer que o debate está aberto em torno da necessidade de incrementar a produção e a veiculação de textos acadêmicos completos em ambiente virtual, no sentido de se configurar uma "inteligência computacional" e uma "biblioteca universal digital". Nada disso elide a existência de bibliotecasfísicas dinâmicas e atualizadas à disposição dos nossos programas de pós-graduação e da comunidade acadêmica em geral. Ambos ambientes devem facilitar e favorecer a manipulação, virtual e física, de textos acadêmicos de qualidade, metadados, autoarquivos, documentos. 


\section{REFERÊNCIAS}

CAPES. Plano Nacional de Pós-graduação- 2005/2010. Brasília, 2004. Disponivel em: http://www.capes.gov.br/capes/portal/conteudo/10/PNPG.htm. Acesso em Agosto de 2006.

CAPES. Resultado Final - Avaliação 2004. Brasília, 2004. Disponível em: http:// servicos.capes.gov.br-2003_038_Sintese.pdf. Acessado em Agosto de 2006.

CAPES/DAV. O que é o Qualis. Brasília. Disponível em: http://www.capes.gov.br/ capes/portal/conteudo/Oque_e_Qualis.pdf. Acesso em Agosto de 2006.

CASTELLS, Manuel. A sociedade em rede. São Paulo: Paz e Terra, 2000.

CHARTIER, Roger. A aventura do livro: do leitor ao navegador. São Paulo: Editora Unesp, 1999.

COHEN, Joel. Computer mediated communication and publication productivity among faculty. Eletronic Networking Application and Policy, v. 6. n. 2/3, 1996.

COSTA, Sely Maria de Souza; DA SILVA, Wagner Augustus; COSTA, Marcos Bizerra. Publicações científicas eletrônicas no Brasil: mudanças na comunicação formal, também? Revista de Biblioteconomia de Brasilia, v. 25, n. 1, 2001.

COSTA, Sely Maria de Souza; MEADOWS, Jack. The impact of computer usage on scholarly communication among social scients. Journal of Information Science, v. 26, n. 4,2000 .

DIAS SOBRINHO, José; RISTOFF, Dilvo. (orgs.) Avaliação Democrática: para uma Universidade Cidadã. Florianópolis: Insular, 2002.

ECOFUTUR0. Brasil, Brasileiros e Bibliotecas. Disponível em: www.ecofuturo. org.br/JN.asp Acessado em Agosto de 2006.

FONTES, Virgínia. História e Verdade. In: FRIGOTTO, Gaudêncio; CIAVATTA, Maria. Teoria e Educação no labirinto do capital. Petrópolis: Vozes, 2001.

GAMA, Zacarias Jaegger; COELHO, Daniel Beridian; CAMELO, Jordan Aragão. Avaliação Educacional: Geografia de textos na Internet - explorações iniciais. Revista Iberoamericana de Educación, n 45/1, janeiro de 2007. Disponível em: http://www.rieoei.org/deloslectores/1485Gama.pdf . Acesso em fevereiro de 2007.

IBOPE. $17^{a}$ Pesquisa Internet POP. Rio de Janeiro: IBOPE, 2005 Disponível em: http://www.ibope.com.br/calandraWeb/servlet/CalandraRedirect?temp $=6 \& p r o j=$ 
PortalIBOPE\&pub=T\&nome=home_materia\&db=caldb\&docid=69AFC5D7C5D CE45283257018006F46BB. Acesso em novembro de 2007.

IBGE. Sistema IBGE de Recuperação Automática. Tabela 2387. Rio de Janeiro: IBGE. Disponível em: www.sidra.ibge.gov.br . Acessado em outubro de 2005.

IBICT/MEC. ISSN. Brasília, 2003. Disponível em: http://www.ibict.br/secao. php?cat=ISSN Acesso em Agosto de 2006.

KAMINER, Noam; BRAUSTEIN, Yale M. Bibliometric analysis of the impact os Internet use on scholarly productivity. Journal of the American Society for Information Science. v. 49, n. 8, 1998.

KOSIK, Karel. Dialética do Concreto. Rio de Janeiro: Paz e Terra, 1976.

VOORBJI, Henk. J. Schearching scientific information on the Internet: a Duth academic user survey. Journal of the American Society for Information Science, v. 50, n 7.1999 . 